\title{
UNDERSTANDING "JOINING-UP-GOVERNMENT" REFORMS IN ANGLO-SAXON NATIONS FROM A CULTURAL POINT OF VIEW
}

\author{
Charf eddine Benouareth \\ PhD Student in Comparative Public Administration, \\ Laboratory of Transition Politico-Economique \\ et Social Dont le Cas de l'Algérie, Université Kasdi Merbah Ouargla. \\ Address: 207 Benkhalde Sadek Str., Gouicem, 41000 Souk Ahras, Algeria \\ E-mail: benouarth.charfeddine@univ-ouargla.dz
}

\section{Miloud Gacem}

Professor of Political Sciences, Laboratory of Transition Politico-Economique et Social Dont le Cas de l'Algérie, Université Kasdi Merbah Ouargla Address: City Nacer s b 5 n 197, 30000 Ouargla, Algeria.

\begin{abstract}
This paper looks at how culture affects the reform process and how cultural factors play an important role in clarifying administration models. Culture is considered as an important variable that interacts differently from one situation to another and from one place to another, therefore, Anglo-Saxon administrations have experienced several phases and many transformations (public administration, new public administration). Due to many obstacles (economics squeeze, the poor performance), both PA and the NPM have failed to capture the delivery and management of public services in the twenty-first century, which has created momentum for actors to look for efficient public services delivery by creating a more integrated public sector. New public governance (NPG) appeared in the literature as a new model looking towards a more integrated public service, combining several players (private sectors, civil society) working on delivering service in the best possible manner. As a result, Anglo-Saxons countries have proceeded many reforms. The joining-up-government strategy is considered as the latest manifestation of NPG after the negative effects of NPM. Research on Joining up Government (JUG) has a long tradition. It has been used for many years in the field of public administration and was widely welcomed in the mid-1990s in numerous Anglo-Saxon countries as a response to the failure of new public management in the public sector, which was at that time far from being well-coordinated. Consequently, the JUG strategies have been proposed to redress this failure, and to that end, several actors play significant roles in the success of these strategies. But, in return, there is a necessity for a number of cultural arrangements between these players. However, these arrangements are dependent on the dialectic of cultural values that are adopted by those society nations. Geert Hofstede, like many researchers in the cross-culture field, tried to adopt cultural dimensions to explain the differences between the many nations that carry different cultural values. From this standpoint, this paper tries to explain JUG in Anglo-Saxon countries by using Hofstede's cultural dimensions.
\end{abstract}


Keywords: New public management; post-NPM; joining up government; AngloSaxon nations; cultural value.

Citation: Benouareth, Ch. \& Gacem, M. (2019). Understanding 'Joiningup-Government' Reforms in the Anglo-Saxon Nations from a Cultural Point of View. Public Administration Issue, Special Issue I (electronic edition), pp. 27-45 (in English); DOI: 10.17323/1999-5431-2019-0-5-27-45.

\section{Introduction}

Research on public administration has a long tradition. This research formed a relatively new area which has emerged post new public management (postNPM) after decades of this pattern of administration suffering from several disadvantages. It is therefore imperative to reconsider its underlying philosophy.

There are a growing number of voices calling for the implementation of what are called post-NPM models (New Public Governance). In this context, Osborne described new public governance as "the shadow of the future" to respond to the challenges of public policy implementation and public services delivery in the twenty-first century (Osborne, 2010). Joining Up Government (JUG) strategies, in particularly, are undergoing a revolution and are more widely used at this time, thus attracting considerable appraisal from most scholars focused on explaining the reasons that pushed these strategies to appear in the first place, which mainly revolve around providing cohesive services instead of the fragmented services offered under new public management.

A common technique under this method is to return to coordination between all departments, and even further, the dependency on the engagement of the private and third sectors. However, this method greatly needs certain cultural alignments between the different actors who participate in this process. Initially, this method was introduced in the United Kingdom, and slowly it has expanded to encompass several Anglo-Saxons countries (Canada, New Zealand, Ireland, and United States).

For decades, cultural approaches played a major role in many fields when exploring the hidden sides of the phenomena, especially when it comes to exporting and importing administrative models from one society to another, since the existing differences in cultural values will result in difficulties in adapting the imported models for cultural reasons.

A lot of studies have shown cultural effects on administrative reform. Seminal contributions have been made by Geert Bouckaert in his previous work, which has only focused on a cultural explanation of the outcomes of the New Public Management. Similarly, some researchers, such as Eva Beuselinck, Koen Verhoest and Geert Bouckaert, have also studied the reforms in central government coordination in OECD-countries. However, they only provided evidence about the central coordination mechanisms.

A number of works have shown that a way to understand administrative reforms, including the JUG strategy, is by using the cultural dimensions that were discovered by Hofstede. It is of interest to know whether the JUG strategies can be applied to other nations that want to develop their administrative regimes. 
The main research questions covered by this paper are: Firstly, what are some of the main features of the JUG strategies as experienced in the Anglo-Saxon models? Secondly, are national reform programmes that relate to joining up government characterized by similarity, or rather by variety and divergence relative to national differences in cultural aspects? Thirdly, how and to what extent can the cultural aspects affect the process reforms? And finally, can other nations that are characterized by different cultural values import the JUG techniques?

In the next section, we attempt to expose the analytical framework for analysing the administrative transformation from new public management and beyond, and at the same time, we shall try to explain the debate between researchers about post-NPM. The subsequent section analyses joining up government characteristics as manifested in Anglo-Saxon countries. Finally, the last section analyses the issue of culture for the countries under study, from cultural dimensions as defined by Hofstede.

\section{Shifting from NPM to post-NPM models}

From the 1980s to the 1990s, most Anglo-Saxon countries experienced a comprehensive NPM reform. However, in terms of the idea, the reform process, and the effects, NPM has been quite different in each of these countries. The size and the range of state activities across Anglo-Saxon countries were increasing to the point that expenses in the public sector represented about 50\% of the GDP. This development led directly to an ineffective administration undermined by many bureaucratic problems, and as a result, a new phase of neo-liberalism tendency evolved, which was led by a Thatcherism philosophy. Francis Fukuyama in his book 'State building: Governance and world order in the 21st century', discusses the range and the power of the state institutions by distinguishing between the state activities scope and the power of the state authority. He claims that the distinction between these two dimensions allows us to understand the power of the state. He also argues that whenever the scope of state activities is retracting in one hand, inversely, on the other hand, the stronger the state institutions become, and, as a result, the state will be moving toward a better economic place (Fukuyama, 2004).

After the economic squeeze and the harsh recession that hit many countries, many of them, including Anglo-Saxon ones, introduced reforms as a solution to achieving effectiveness at economic and administration levels, through hitting the hart of their bureaucracy in a comprehensive manner, based on three components (marketization, disaggregation, and incentivisation). Through these strategies, countries such as New-Zealand and the United Kingdom found themselves transforming their administrations, through strengthening the state institutions and cutting back on state activities. These ideas gave rise to a new current phase in public management thinking, labelled NPM (Hood, 1995).

Basically, there were three theoretical pillars that played a major role in the establishment of the new model (NPM): Agency Theory, Public Choice Theory, and the managerialism mainstreams. The first of these is based on the contractual relationship between the managers and the agents who work according to the contract conditions, and this became the basis for changing the fundamental nature of the 
public sector (Gruening, 2001). Such beliefs were also acknowledged by Deakin and Michie: "If there is a single strand that runs through the changes brought by the neoliberal revolution ... it is the revival of contract as the foremost organizing mechanism of economic activity" (Deakin \& Michie, 1997, p. 1). The second pillar deals with the assertion that people get services based on self-interest. The third was for overcoming the stagnation that appeared with the Weberian philosophy model by managing the public sector, particularly by monitoring through performance settings and controlling the outputs of the administrative activities and the transfer of responsibilities and freedom by letting managers manage, making them accountable for their results and actions, and making effectiveness the main theme in public management through depoliticization, thus keeping the politicians from interfering in the management process. The main reasons that drove the new public management to appear were to cut back the public sector, which was deemed to be excessively expanded during the previous era of the welfare state, and to move into privatization and market competition. In the same vein, this paradigm generated a complete break from the Weber administration, focusing on the standards which related to the selection criteria of the chief executive heads in the units, drawing attention to citizens needs by making the administration more flexible and harmonizing through disaggregation of the public sector into specialized units and making them compete in providing services by updating the private sector style (McLaughlin et al., 2002).

Under the NPM version, political leaders abstain from the day to day involvement in administration matters so the administrators and the decentralized agencies (rowing) will be guided by politicians (steering) through the outputs. According to Osborne and Gaebler, the role of government "is to steer, not to row the boat because government is not very good at rowing" (Osborne \& Gaebler, 1992, p. 25). Through fixing the budget, selecting the right people at the head of the agencies, and establishing monitoring bodies (Audit Commission) to monitor the performance, New Public Management is an attempt to refashion public services in such ways that they resemble the private sector by bringing the private sector practices into the public sector and removing the differences between them (McLaughlin et al., 2002). However, many critics have emerged in the public management literature discussing new public management: one of the primary problems associated with this pattern of administration is the fragmentation and specialization resulting from single-purpose agencies, which leads directly to a myriad of problems in public administration. Also, many scholars have remarked that the first wave (the new public management) was characterized by lack of coordination and control between agencies and, under the new public management, coordination was made more difficult partly because the incentives to achieve each organizations aims were greater than the incentives to achieve system-wide objectives. "Osborne and "Gaebler" argue that the new public management separates 'steering from rowing', leaving the centre to steer while other agencies row (Osborne \& Gaebler, 1992, p. 35). But the question that should be asked here is whether the competition posed by the NPM Philosophy made the agencies row in a competitive manner (anarchical rowing) without coordination, therefore the boat (the public sector) may sail randomly, which makes the objectives hard to achieve. In this context, 
the former New Zealand Minister of State Services, Trevor Mallard, commented in one of his speeches that "departments compete against each other to hire the same staff, sometimes to the detriment of the Government overall" (Massey, 2011, p. 77). There is a further problem related with social inequalities and the low quality of the services provided by the government. Moreover, "NPM" creates a weaker control by the superiors over the subordinates, caused by the fragmentation. (Lynn Jr, 1998a). These fragmentation problems (the spatially and functionally fragmented) require a multi-agency response and varied solutions, as stressed by Tim Clark "the solutions to problems are not sought through the traditional means of individual government departments but rather through varied means according to the nature of the problem" (Clark, 2002, p. 108). All of the AngloSaxon administrations have witnessed a lot of reforms, from the bureaucratic model to the post-NPM models. Every reform has many reasons and special logic, furthermore, every model comes on the ruins of the others that have been passed, (1) the Weberian model has a perceived lack of performance responsibility, transparency, control and policy capacity to guarantee results, (2) these have led to new solutions, i.e., the creation of agencies, more autonomy and specialization, (3) but these solutions generated the loss of control by the centre and a fragmented public sector where the NPM is designed to resemble the prism effects, therefore, when the light goes through the prism, the light will fragment to different colours, indeed, this is what happened to the public sector under the NPM model, (4) so, to transcend these problems, the reform actors proceeded with new strategies to redress the new public management failure in a manner where all the players have to provide services interdependent from NPG by adopting new techniques like coordination by (5) horizontal integration and (6) vertical integration (see Figure 1).

\section{Figure 1: The transformation from bureaucratic to post-NPM models}

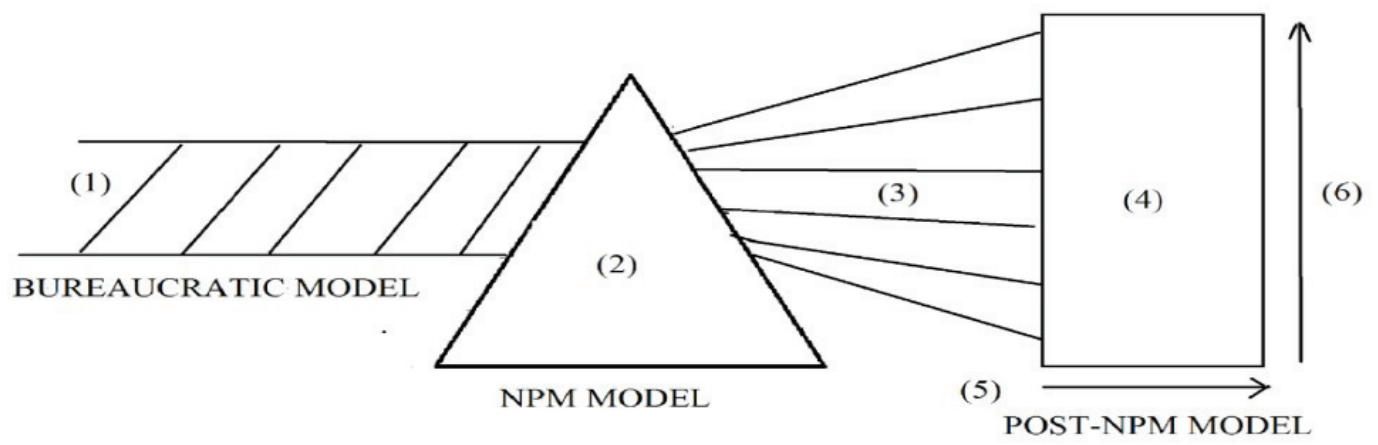

Source: Composed by the authors.

Many works of literature consider post-NPM to be the second generation of reforms. However, we acknowledge that there are considerable discussions among researchers and some of them take into consideration the difficulties that appeared in defining the surrounding aspects of these reforms. For instance, 
Christopher Pollitt and Geert Bouckaert, in the introduction of their book, assert with regard to the complexities related to these paths, as follows: "... as the 1990s progressed, its 'personality' began to change... Talk turned to governance, partnerships' 'joined-up government, whole of government' and then to 'trust' and 'transparency. In other words, the agenda seemed to shift. This was a complex process ..." (Pollitt \& Bouckaert, 2004, p. 7)

Others see that the NPM model as a thing of the past, as Lynn stressed: "Most of us could write the New Public Management is post-mortem now" (Lynn Jr, 1998b, p. 232). Some argue that alternative patterns, such as E-government, are beyond the new public management. As Patrick Dunleavy in his analysis of the emergence of digital era governance states, "we would argue for the first time, it now makes sense to characterize the broad sweep of current public management regime change in terms that refer to new information-handling potentialities, which make feasible a transition to fully digital modes of operating for many government sector agencies" (Dunleavy et al., 2006, p. 487). There are reasons to question this explanation. For instance, many researchers considered that the IT information technologies are a sub-tool to reinforce either NPM or post-NPM models. In the same vein, Christopher Pollitt and Geert Bouckaert claim "the point to make here is that e-government is not a model in itself. Neither does it line up exclusively with any one of the models mentioned NPM, networks, governance, etc." (Pollitt \& Bouckaert, 2017, p. 7). Many scholars have focused on this evidence, yet not everyone agrees that this is the most important aspect of the situation.

\section{Joining up government to redress the failure}

The complexity of the service delivery, and furthermore, the competition that was composed by new public management in different public sectors, made the scholars and reformers seek ways and solutions to deliver the services in the desired form, particularly with the appearance of new players in the backyard of the public sectors (private sector, civil society) who pushed for service delivery in a more integrated way in which everyone participated in it, by creating networks that coordinate public sector work. In this context, there were several theories and proposals by many scholars in the management field (new public governance, good governance). Different Anglo Saxon governments tried to translate these theories into real programmes and strategies, among them joining-up-government (Osborne, 2010).

Overall, the problems that appeared in the heyday of the new public management pushed the governments to seek out new methods to increase efficiency and effectiveness and so on. All Anglo-Saxon countries followed new paths in order to reform their administrations, through moving toward a pragmatic response to the problem, where the complexity of these problems and their cross-cutting nature demanded that organizational boundaries be more blurred (Keast, 2011). With this in mind, the reform was through introducing a solution called whole-ofgovernment (WOG), as used in Australia, or joining-up-government approaches (JUG), a slogan that originated in the United Kingdom (Bouckaert et al., 2016; 
Castellani, 2018; Christensen \& Lægreid, 2007; Exworthy \& Hunter, 2011; Khan \& Musarrat, 2016; Perri, 2004; Pollitt, 2003; Pratchett, 2003; Song, 2018). In other words, JUG tends to proceed with a new organisational perspective that clashes with the existing one (Exworthy \& Hunter, 2011). In short, JUG has been linked to and was accepted with enthusiasm in many Anglo-Saxon countries (Christensen \& Lægreid, 2007; Khan \& Musarrat, 2016). At first glance, the joining up strategy seems to be a new pattern, while many researchers consider this pattern of administration as old as the public administration (Durose \& Rummery, 2006; Imperial, 2005). Therefore, in this context Pollitt asserts that the joining up strategy is new but it seems to be the latest manifestation of one of the oldest perceptions in the field of politics and public administration (co-ordination of policy-making and administration) (Pollitt \& Bouckaert, 2004). In another context, as we mentioned above, many researchers in the field claim that the Post-NPM models (like NPG) suggest several strategies which are rooted strongly within institutional and network theory (Powell et al., 1996).

In the literature, joined-up-governance tends to be used to refer to a strategy that aims to coordinate and implement policies across a government structure, in other words, it means the instruments and mechanisms that aim to enhance the voluntary or forced alignment of tasks and efforts of organizations within the public sector. Also, these mechanisms are used in order to create a greater coherence and to reduce redundancy, lacunae and contradictions within and between policies. Several authors have attempted to define JUG, but at the time of writing this paper, there is still no accepted definition. In the field of public management, many definitions of JUG can be found. The term has been used by Perri who defines JUG as "the consistency between the organizational arrangements of programs, policies, or agencies which may enable them to collaborate" (Perri, 2004, p. 106).

From this standpoint, we may consider that there are many reasons for the government's introduction of JUG. From the empirical overview, the slogan of "whole-of-government" expresses the ambition to manage horizontal and vertical coordination in order to reduce states in which different policies undermine each other by integrating service delivery and making collectively government services in one area, and adopting flat government approaches like traditional coordination mechanisms, not to mention making better use of limited resources, and improving cost-effectiveness by removing overlaps, to generate synergies by taking together different stakeholders (Private-public partnerships) and encouraging teamwork, information sharing and incentivising working together in a particular policy area and to give citizens the best access to services rather than fragmented access, tighter links between service entities delivers by creating seamless services, one-stop shops and user-friendly, holistic and efficient provision of services (Keast, 2011; Pollitt, 2003). Jack Cunningham, the previous Minister for the Cabinet Office of the United Kingdom, stated that "to improve the way we provide services, we need all parts of government to work together better we need a joined-up government we need integrated government" (Tony Blair \& Cunningham, 1999, p. 6). So, in short, it can be considered as a collection of responses to the perception that services had become fragmented and 
that this fragmentation was limiting the success of important goals of public policy. "Tom Christensen" summarizes the methods that have been introduced by many Anglo-Saxon countries, which are: (Christensen \& Lægreid, 2007)

1. Increasing the control by the top leaders

2. Extending horizontal control by different departments

3. Cross-sectorial coordination "super-networks"

4. Coordinate activities between and across organizational boundaries (interdepartmental, centre-local, communities, voluntary bodies, and different stockholders).

Ling, in his pragmatic typology, draws our attention to the dimensions associated with JUG which are as follow: new ways of working across organisations (joined by shared leadership, pooled budgets, the-Invest-to-save budget, merged structures, joint teams, and shared agenda), new types of organization (joined by culture and values, whole change of culture information), new ways of delivering service (joined by consultation, shared client focus customer/client focused, shared customer interface, new accountabilities and incentives (shared outcome targets, performance measures, regulation) (Ling, 2002, pp. 625-631).

The practices associated with joined-up government are varied and differ from one context to another. Figure 2 demonstrates the dimensions that are associated with how to achieve JUG. Consequently this is done through increasing cooperation and coordination tools which link up efforts at local, regional, and international level as well as various government sectors. JUG requires not only government departments and agencies, but also independent bodies and civil societies, to operate across organizational boundaries through one common objective of delivering service (see Figure 3) (Khan \& Musarrat, 2016). At this stage of understanding, we believe that to achieve the purposes of the joining up government approach, there are two dimensions that must be attained: the first one is the vertical form (from top to down): this method can be used by the political leadership and the official body as an integration strategy which flows down (from central to local level to management and service levels). As a result, this strategy will be translated as law after negotiation and bargaining with the civil servants. The other form, coupled with the first one is the horizontal integration: this method stands on the integration emerging from the service delivery front that often precedes it for many reasons (scarcity of resources, working condition etc.). Notably, from the information laid out above, we conclude that in essence joining up strategies are an attempt to integrate new bodies (stakeholders) in public matters, rather than governing by a singular body (Rhodes, 1997). JUG contains many actors and can have several kinds and forms (public-private sector, public and voluntary sector, the state and the individual and between statutory sectors) (Balloch \& Taylor, 2001).

To proceed with a new joining up strategy, there might be a significantly important need to guarantee that all actors follow the same direction. However, this guarantee can be found in the forms and types of relations and the links that control the actors. To give an illustration (formal, informal or contractual), there might also be another indicator that has an important effect and that can appear through the quality of the relationships, for instance (higher trust relation or lower 
one), between the actors. From a structural point view, another important aspect, however, is that we know all that these actors act inside a certain structure, but the type of structure plays a pivotal role in the success of strategies for joining up. Despite this, we can find two types of structure: the first one brings an equal structure which can occur between, for example, the public and voluntary sectors or the public and private sectors. Also we can define two levels of joining up working at national and local level (Davies, 2009).

Many researchers and public bodies have tried to identify JUG strategies needed for putting the joining up strategies in the right paths. In view of a "wiring it up" report by the cabinet office, five themes of recommendations for improving JUG were identified (Great, 2000):

1. Leadership for cross-cutting policies \& services: value and reward cross-cutting activity, ensure career progression linked to policy experience.

2. Improving cross-cutting policy-making: make better use of outside experts.

3. Skills for cross-cutting policies \& services: encourage the interchange of staff between departments and with external agencies.

4. More flexibility in the funding of cross-cutting policies: institute changes in parliamentary procedures.

5. Getting a role of the Centre-right: articulate better corporate government goals, ensure effective performance management and information systems.

In another part, Sullivan and Skelcher work on which ways in which different stockholders can facilitate the joining up working by identifying components that linked both actors who want to move toward jointly working with these components, including the understanding of collaborative and partner issues, overcoming existing institutional cultures, establishing a strategic vision, ensuring available resources and capacity, formalizing the relationships and criteria for working together and developing appropriate communications and performance frameworks (Sullivan \& Skelcher, 2017).

This method is not without problems, as there may well be risks in these strategies. Pollitt argues that the costs in tracking the joining up in the government, in many aspects regarding different actors joining in through several processes of the JUG may lead to higher risks of failure (because of complexity, irreconcilable disagreements, obscure accountability arrangements) (Pollitt, 2003), as well as the fragility of JUG. This pushed the Cabinet Office to launch an initial review of cross-cutting issues, "By their nature, cross-cutting policies tend to have more stakeholders, be harder to monitor and evaluate; and run greater risks of failure and communications breakdown" (Great, 2000, pp. 7-8). In this review, the cabinet office identified the problems that can appear, and which can be faced by employees and civil servants. Among these problems were less clear lines of accountability for policy and service delivery, greater difficulty in measuring effectiveness and impacts, the need to develop and maintain more sophisticated performance measurement systems, direct and opportunity costs of management and staff time spent establishing and sustaining cross-cutting working arrangements. Therefore civil servants must learn how to communicate faster with a wider range of stakeholders; they need to acquire new skills, organizational and transitional costs of introducing cross-cutting approaches and 
structures (Great, 2000). Khan and his colleague summarized the risks and challenges that could stand in the way of JUG: lack of cooperation in the implementation between levels of government, lack of consideration of the division of responsibilities among levels of government, lack of training in accomplishing the priority task of the government, and limited cooperation with civil society organizations in the field (Khan \& Musarrat, 2016). Another key thing to remember is that the civil society is considered as one of the important numbers in the joining up working, however from the logic of 'survival of the fittest', JUG formation could lead to net losses for the voluntary sector in facing the logic of profit for the private sector.

To proceed in these approaches, there must be a form of cultural alignment among these different organizations (aims and management systems). There are different styles and methods which different Anglo-Saxon countries have applied to achieve this end.

\section{Understanding joining-up-government from a cultural perspective}

Much attention has been drawn to the importance of culture as an aspect of administrative reform (Bouckaert, Hofstede, 1998; Oliver \& Cravens, 1999; $\mathrm{Xi}, 2016)$. Therefore, if we want to learn much more about administrative reform, we should look at it from cultural angles. "In the 1950s and 60s, the dominant belief, at least in Europe and the U.S., was that management was something universal" (Hofstede, 1983, p. 75), but obviously, from another side , cultural differences have a different impact on public administration, the reforms packages are studied in depth to ensure their alignment with the cultural values of the society, and therefore there is no doubt that the paths of the administrative reform are influenced by the culture society values, since the essence of culture is not what is visible on the surface but significantly it can be considered as shared ways for groups of people to understand and interpret the world. As mentioned by Hofstede, who supports this idea pointedly "management methods are not value-free" (Hofstede, 1984, p. 96).

The term culture has been said to be one of the most complicated words. In the literature culture usually refers to an attempt to explain differences in the behaviour of diverse groups of actors in situations that are objectively alike (Schedler \& Proeller, 2007); in comparison with Hofstede's work where he defines culture as a gene pattern across generations and in this context culture is defined by him as "the collective programming of the mind which distinguishes the members of one group or society from those of another" (Hofstede, 1984, p. 82). The research of Hofstede into national cultures was carried out between 1967 and 1978 in attempt to meet an objective: to develop a commonly acceptable, well-defined, and empirically based terminology to describe cultures by collecting the data about a large number of cultures, rather than just only impressions. According to him in this research, based on IBM data from around the 1970s, initially four, then five dimensions were relevant: power distance, individualism/collectivism, masculinity/femininity, uncertainty avoidance, and time span, furthermore, he added another sixth dimension, namely indulgence (see Table1). 


\section{Cultural dimensions by Geert Hofstede}

\begin{tabular}{|c|c|}
\hline \multicolumn{2}{|c|}{ Power Distance: (PD) The extent of acceptance of distribution of power inequalities } \\
\hline Culture rejects distribution of inequalities of power & $\begin{array}{l}\text { Culture accepts distribution of inequalities } \\
\text { of power }\end{array}$ \\
\hline $\begin{array}{l}\text { This culture is working on fighting inequality in the } \\
\text { distribution of power between people and the } \\
\text { opportunity of progress and development available } \\
\text { for all, therefore. This culture does not take into } \\
\text { consideration the differences between people and } \\
\text { it does not believe in the distribution of unequal } \\
\text { power between their members and the power-use } \\
\text { between people should be done in a legitimate } \\
\text { manner }\end{array}$ & $\begin{array}{l}\text { The inequalities in distribution of power } \\
\text { between people in this culture are acceptable } \\
\text { and normal. People in these societies accept } \\
\text { the hierarchical order, the subordinates are } \\
\text { not expected to express their disagreement } \\
\text { with superiors because there is no opportunity } \\
\text { of superiority for all, therefore, they give the } \\
\text { most importance to the differences between } \\
\text { people in terms of power distribution }\end{array}$ \\
\hline
\end{tabular}

Uncertainty avoidance (UA):The extent to which risks and the uncertain conditions are faced

Cultures which avoid the risks and uncertainty conditions
Cultures which do not avoid the risks uncertainty conditions

In spite of the risks and the uncertainty of conditions in this culture, people still have the ability to go on toward ventures
This culture gives more attention to the organization's rules, it also stands on obedience and serious working and the ambiguous feeling that spreads between people

\section{Masculinity/femininity (MAS): The extent orientation by masculinity versus femininity}

\begin{tabular}{l|l} 
Culture oriented by masculinity & Culture oriented by femininity
\end{tabular}

In these societies, the tendency is toward the distinction between the genders that supports the control of men who are characterized by assertiveness and toughness, furthermore, they focus on material success
On the other hand, in societies which are the dominated by femininity, the tendency is toward equality between the genders and the roles overlap between them. Furthermore, these societies focus on the improvement of life quality

Individualism/collectivism (DV): domination by individualism versus collectivism

\begin{tabular}{l|l} 
Individualism cultures & Collectivism cultures
\end{tabular}

These societies focus on self-interest and the ties between people are loose; everyone looks after themselves and their immediate family
On the contrary, in collectivist cultures, people are expected to be interdependent, and must show loyalty to their extended family and/or to the in-group to which they belong

\section{Short-term orientation versus long-term orientation (LTO)}

\begin{tabular}{|l|l|}
\hline Short-term orientation & Long-term orientation \\
\hline $\begin{array}{l}\text { In this culture, people focus on personal stability } \\
\text { and caring about the present }\end{array}$ & $\begin{array}{l}\text { In this culture, people focus on some values like } \\
\text { perseverance, determination and savings }\end{array}$ \\
\hline \multicolumn{1}{|c|}{ Indulgence (VR): High indulgence versus low indulgence } \\
\hline High indulgence society & Low indulgence society \\
\hline $\begin{array}{l}\text { In this culture, there are no strict social norms, } \\
\text { hence people can achieve their needs and desires, } \\
\text { and as a result, they are supposed to be happy }\end{array}$ & $\begin{array}{l}\text { In this culture, people live under strict social } \\
\text { norms; their needs are suppressed and regulated }\end{array}$ \\
\hline
\end{tabular}

Source: (Hofstede et al., 2010). 
As we mentioned above, the joined-up government is a complex system layered with multiple sectors and levels, and, yet again, the success of this approach depends on the extent of acceptability of cultural values by society (Hyde, 2008). The argument is that there is a need to re-establish a common and cohesive culture in the public sector; therefore, all agencies should be bound together by a single, distinctive public service ethos. Under whatever slogans are used in describing the joining up working, all Anglo-Saxon governments emphasized the need to build a supportive public-sector culture that encourages whole-of-government solutions by formulating value guidelines and codes of conduct (Shergold, 2005). From the short review above, some key findings emerge:

Table 2

\section{Cultural dimensions indexes}

\begin{tabular}{|l|c|c|c|c|c|c|}
\hline \multicolumn{1}{|c|}{ Country } & PDI & IDV & MASI & UAI & LTOI & IVR \\
\hline United States & 40 & 91 & 62 & 46 & 26 & 68 \\
\hline Australia & 36 & 90 & 61 & 51 & 21 & 71 \\
\hline New Zealand & 22 & 79 & 58 & 49 & 33 & 75 \\
\hline UK & 35 & 89 & 66 & 35 & 51 & 69 \\
\hline Ireland & 28 & 70 & 68 & 35 & 24 & 65 \\
\hline Canada & 39 & 80 & 52 & 48 & 36 & 68 \\
\hline France & 68 & 71 & 43 & 86 & 63 & 48 \\
\hline Italia & 50 & 76 & 70 & 75 & 61 & 30 \\
\hline Spain & 57 & 51 & 42 & 86 & 48 & 44 \\
\hline
\end{tabular}

Source: (Hofstede et al., 2010).

Note: France, Italy and Spain (the Napoleonic countries) have been added as examples to show the differences in cultural values between these nations, and also to clarify that the Anglo-Saxon nations as a model, have special cultural values.

According to Hofstede, the divisive culture dimensions in any organization are the uncertainty avoidances (UA) and power distance (PD). Organizations are working on distributing authority (delegation) and they also serve to avoid uncertainty (ambiguous cases). Figure 2 shows that the Anglo-Saxon cluster is characterized by low PDI. We notice among these countries New Zealand scores the lowest value in this index, and the United States comes in the lead in IDV. Similarly Ireland scores highest in MAS, although there is convergence between the other countries like the UK, New Zealand, Australia, and the United States. Surprisingly we find that Ireland and the UK score the same lowest value index with regard to UAI. Another key point to remember is that, regarding the time cases, we find that Australia scores the lowest value index in LTOI, followed by the United States. On the other side, we see that the Napoleonic cluster is characterized by highest value index UA, especially Italy and France, and not only in UAI, but also scoring the highest value index regarding PD. On the other hand, we see that France and Italy also score the highest value index in LTOI (see Figure 3). 


\section{Figure 2: Cultural indexes in Anglo-Saxon countries}

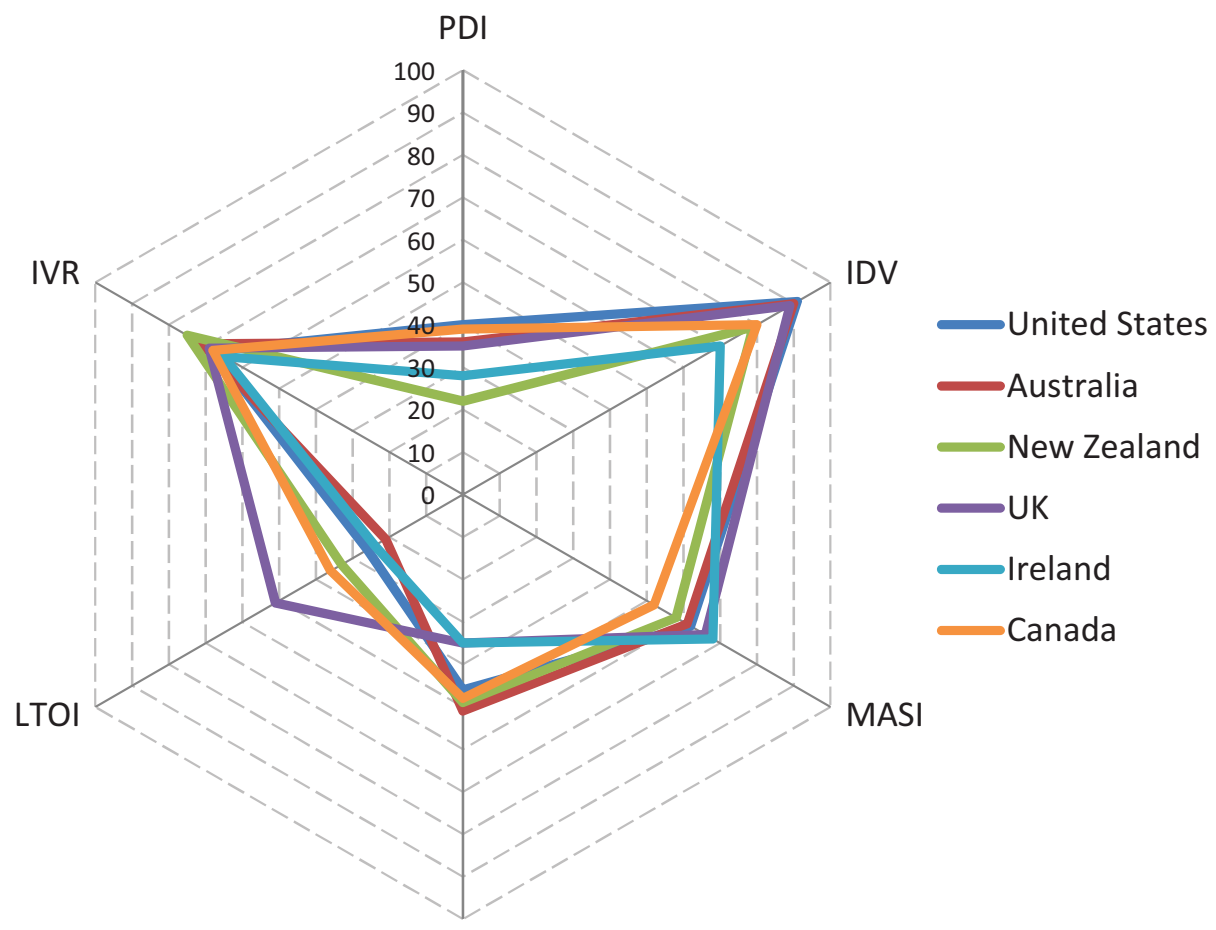

UAI

Figure 3: Cultural indexes in Napoleonic countries

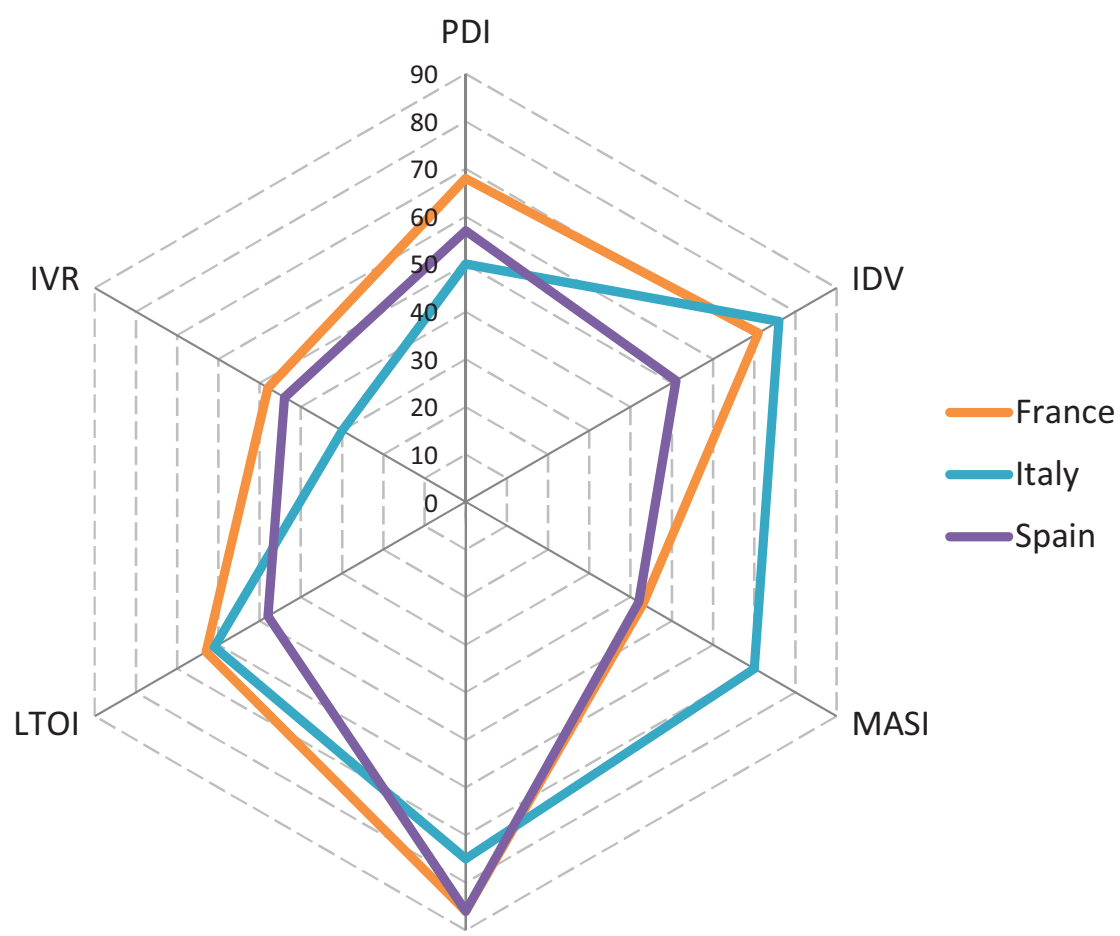


In one way or another, the culture society value plays a pivotal role in defining the success of a joining up government program, as well as in how the culture platform identifies the capability of those reform programs. In conclusion, to understand the interaction between culture and joining up government reform, we should analyse how the culture variables, as mentioned by Geert and Hofstede, affect the success of JUG. Moreover, we should look into the acceptability of the community (employees, individuals, departments, local governments, private sectors, voluntary sectors) in regards to this package.

\section{Low Uncertainty avoidance index}

and the tendency to renew and to adventure

There are differences between nations' cultural values in their aptitude for renewing and for adventure. Obviously this tendency is associated with the low uncertainty avoidance values that we find it in the Anglo Saxon models, where their people are thirsty for change and adventure and are open to further reforms. To that end, there is no doubt or hesitation in the implementation of joining up government.

\section{Figure 4: PPP projects from 1990 to 2016}

10000

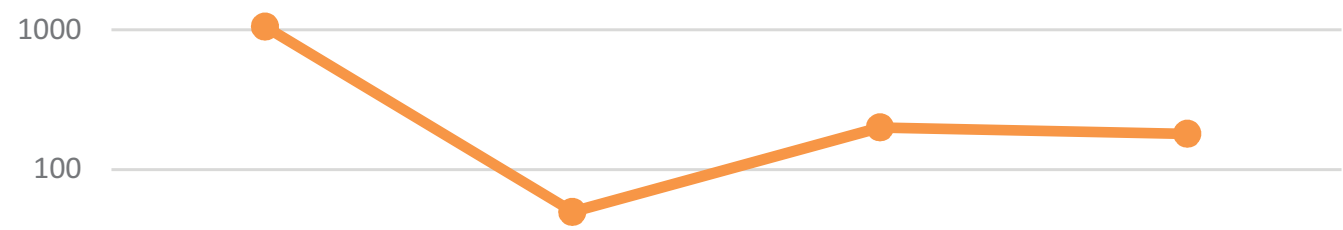

10

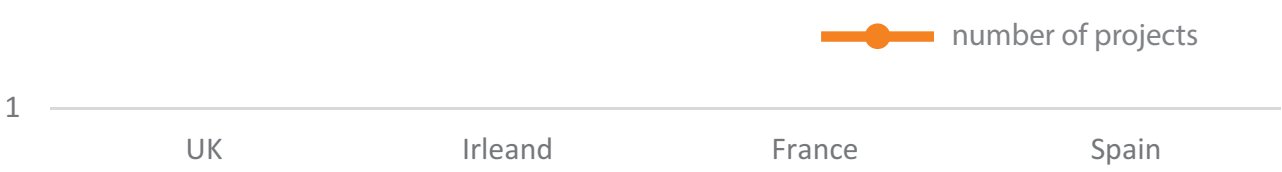

Source: (European Union, 2018).

Figure 4 shows the private-public partnership, where the private sector works in providing services. This partnership is considered as a pivotal factor in joining up strategies, but this form of partnership is determined by the readiness for partnership among the actors and their willingness to proceed in joining up working. The Figure 2 shows that in the United Kingdom, which is characterized by low UAI, we notice that the number of projects between the private and public sector reaches the highest levels in reform times where the JUG was introduced strongly from the year 1990 to 2016 and witnessed approximately 1000 PPP projects, which explains the adventure spirit of the private sector, and which 
gives an impression that the cultural value for the UK society encourages it to go further in joining up working, even in the midst of the economic crisis that hit the world in 2007. In comparison with cultural values that are held by the French, Spain and Italy societies, we find the factors of stability and fear of adventure and renewal are clearly shown in the private sector tendency, where the number projects of PPP type are very low.

It is important to highlight the fact that, despite the obstacles to which the voluntary sectors are exposed, they are still playing a major role in the success of joining up strategies. Another promising finding was that the extent of integration for the civil society in joining up working with the government is determined by the extent of UAI. From Figures 3 and 5, we notice at first glance that there is an inverse relationship between uncertainty avoidance and the average time volunteering, therefore, if there is a higher UAI, there is a decrease in the average time volunteering, and vice versa, if there is a lower UAI, there is an increase in the average time volunteering. This implies that Anglo-Saxon countries are apparently distinct from the rest, i.e., the voluntary sectors in the Anglo-Saxon countries spend more time in providing services, with New Zealand in the lead followed by countries, most of which are Anglo-Saxon nations. (See Figure 5)

\section{Figure 5: Time spent volunteering, \%}

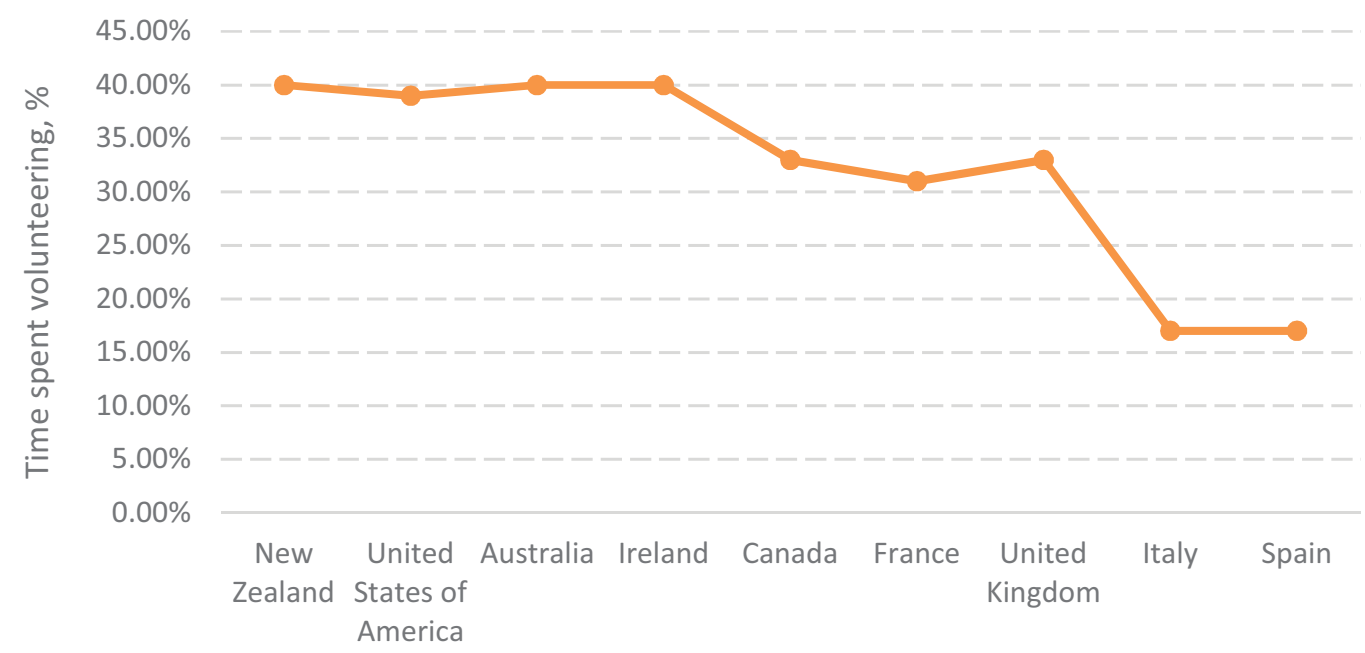

Source: (Charities, 2018).

\section{High Masculinity index and the extent of reform readiness}

It is interesting to note that, a high MASI score on this dimension indicates that the society will be driven by competition, achievement and success. Competitiveness between people is seen as a good thing: the strong should win. In fact, this is what affects the readiness for reform, whatever the content of the reform in this society is, it will be taken seriously and considered a challenge that must be achieved. The principal objective is to create individual jobs that are more inter- 
esting by giving workers a bigger challenge. From Figure 4 and Table 1, we notice that the Anglo-Saxons as societies are characterized by the highest index in masculinity. This is particularly important in regards to achieving this strategy and explains more, i.e., that any further joining working does not constitute any problem to the different actors who participate in working for common teams (Hofstede et al., 2010). In a feminine society, solidarity between people is seen as a good thing: the strong should help the weak and social justice is an important value, people in these societies try to maintain the stability and establish informal relationships in the workplace (Schedler \& Proeller, 2007).This constitutes a possible obstacle for serious administrative development.

\section{Conclusion}

The paper concludes by arguing that Anglo-Saxon countries under certain assumptions, as outlined above, can be construed as holding cultural values which allow them to proceed with more joining up working without uncertainty. Moreover, this may explain why these countries qualify for any reform which keeps pace with environmental development. This is clearly shown by the transformation that occurred over four decades of time from bureaucratic to post-NPM models. The challenge, spirit and assertiveness which characterize Anglo-Saxon societies push them on to further administrative development, and whatever changes occur in these societies, they will inevitably be applicable to cultural values. There is no way to export these reform packages unless the importing country is characterized by the same cultural values, but if there is partial importation with incrementalism reforms and work on cultural values changing in the long-term, in this case, success could be possible, although, there is no evidence to support this claim.

Our findings on this issue at least hint that there is also an inverse relationship between the uncertainty avoidance index and the masculinity index, therefore, if there is weak uncertainty avoidance, inevitably there is a masculine society. This is an important finding in the understanding of the Anglo-Saxon cluster and, vice versa, where there is strong uncertainty avoidance, there is inevitably a feminine society (Napoleonic cluster).

Furthermore, despite the obstacles that may exist on the ground and that can be met by the civil society, there is low uncertainty avoidance, which paves the way towards a larger involvement in providing services. Also this dynamic may encompass the private sectors, especially in a perfect environment (rule of law, incentives etc.). Despite these variables, the success of reform requires cultural bases in harmony with society values, as there is no way to find a remedy to administrative failure by adopting techniques that may differ from the original culture. 


\section{REFERENCES}

1. Balloch, S. \& Taylor, M. (2001). Partnership Working: Policy and Practice, Policy Press.

2. Bouckaert, G. (2007). Chapter 2 Cultural Characteristics from Public Management Reforms Worldwide. Research in Public Policy Analysis and Management, no 16, pp. 29-64. Available at: DOI: 10.1016/S0732-1317(07)16002-4 (accessed: 30 January, 2019).

3. Bouckaert, G., Peters, B. G. \& Verhoest, K. (2016). Coordination of Public Sector Organizations. Springer.

4. Castellani, L. (2018). 1997-2007: Coordination, Consolidation and Delivery in Blair's Government. The Rise of Managerial Bureaucracy: Reforming the British Civil Service. Cham: Springer International Publishing.

5. CAF (2018). World Giving Index. A Global View of Giving Trends. Available at: https:// www.cafonline.org/docs/default-source/about-us-publications/caf_wgi2018_report_ webnopw_2379a_261018.pdf (accessed: 09 September, 2018).

6. Christensen, T. \& Lægreid, P. (2007). The Whole-of-Government Approach to Public Sector Reform. Public Administration Review, vol. 67, no 6, pp. 1059-1066.

7. Clark, T. (2002). New Labour's Big Idea: Joined-up Government. Social Policy and Society, vol. 1, no 2, pp. 107-117.

8. DAVIES, J. S. (2009). The Limits of Joined-Up Government: Towards a Political Analysis. Public Administration, vol. 87, no 1, pp. 80-96.

9. Deakin, S. \& Michie, J. (1997). Contracts, Co-operation, and Competition: Studies in Economics, Management, and Law. Oxford University Press.

10. Dunleavy, P., Margetts, H., Bastow, S. \& Tinkler, J. (2006). New Public Management is dead long live digital-era governance. Journal of Public Administration Research and Theory, vol. 16, no 3, pp. 467-494.

11. Durose, C. \& Rummery, K. (2006). Governance and Collaboration: Review Article. Social Policy and Society, vol.5, no 2, pp. 315-321.

12. ECA (2018). Public Private Partnerships in the EU: Widespread shortcomings and limited benefits. Available at: http://publications.europa.eu/webpub/eca/special-reports/ppp-9-2018/en/ (accessed: 08 November, 2018).

13. Exworthy, M. \& Hunter, D. J. (2011). The Challenge of Joined-up Government in Tackling Health Inequalities. International Journal of Public Administration, vol. 34, no 4, pp. 201-212.

14. Fukuyama, F. (2004). State building: Governance and World Order in the 21st Century. Profile Books.

15. Great Britain: Cabinet Office (2000). Wiring it Up: Whitehall's Management of Cross-cutting Policies and Services: a Performance and Innovation Unit Report. Available at: https://ntouk. files.wordpress.com/2015/06/wiring-it-up-2000.pdf (accessed: 09 November, 2018).

16. Gruening, G. (2001). Origin and Theoretical Basis of New Public Management. International Public Management Journal, vol. 4, no 1, pp. 1-25. 
17. Hofstede, G. (1983). The Cultural Relativity of Organizational Practices and Theories. Journal of International Business Studies, vol.14, no 2, pp. 75-89.

18. Hofstede, G. (1984). Cultural Dimensions in Management and Planning. Asia Pacific Journal of Management, vol. 1, no 2, pp. 81-99.

19. Hofstede, G. (1998). Think Locally, Act Globally: Cultural Constraints in Personnel Management. In: Weber, W., Festing, M. \& Dowling, P. J. (eds.) Management and International Review: Cross-Cultural and Comparative International Human Resource Management. Wiesbaden: Gabler Verlag.

20. Hofstede, G., Hofstede, G. J. \& Minkov, M. (2010). Cultures and Organizations: Software of the Mind, Third Edition, McGraw-Hill Education.

21. Hood, C. (1995). The "New Public Management" in the 1980s: Variations on a Theme. Accounting, Organizations and Society, vol. 20, no 2-3, pp. 93-109.

22. Hyde, J. (2008). How to Make the Rhetoric of Joined-up Government Really Work. Australia and New Zealand Health Policy, vol. 5, no 1, pp. 22.

23. Imperial, M. T. (2005). Using Collaboration as a Governance Strategy: Lessons from Six Watershed Management Programs. Administration \& Society, vol.37, no 3, pp. 281-320.

24. Keast, R. (2011). Joined-Up Governance in Australia: How the Past Can Inform the Future. International Journal of Public Administration, vol. 34, no 4, pp. 221-231.

25. Khan, N. A. \& Musarrat, K. M. (2016). Joined-up Governance. In: Farazmand, A. (ed.) Global Encyclopedia of Public Administration, Public Policy, and Governance. Cham: Springer International Publishing.

26. Ling, T. (2002). Delivering Joined-up Government in the UK: Dimensions, Issues and Problems. Public Administration, vol. 80, no 4, pp. 615-642.

27. Lynn Jr, L. E. (1998a). A Critical Analysis of the New Public Management. International Public Management Journal, vol. 1, no 1, pp. 107-123.

28. Lynn Jr, L. E. (1998b). The New Public Management: How to Transform a Theme into a Legacy. Public Administration Review, vol. 58. No 3, pp. 231-237.

29. Massey, A. (2011). International Handbook on Civil Service Systems. Edward Elgar Publishing.

30. McLaughlin, K., Osborne, S. P. \& Ferlie, E. (2002). New Public Management: Current Trends and Future Prospects. Psychology Press.

31. Oliver, E. G. \& Cravens, K. S. (1999). Cultural Influences on Managerial Choice: An Empirical Study of Employee Benefit Plans in the United States. Journal of International Business Studies, vol. 30, no 4, pp. 745-762.

32. Osborne, D. \& Gaebler, T. (1992). Reinventing Government: How the Entrepreneurial Spirit is Transforming Government. Reading Mass. Adison Wesley Public Comp.

33. Osborne, S. P. (2010). The New Public Governance: Emerging Perspectives on the Theory and Practice of Public Governance. Routledge.

34. Perri (2004). Joined-up Government in the Western World in Comparative Perspective: A Preliminary Literature Review and Exploration. Journal of Public Administration Research and Theory, vol. 14, no 1, pp. 103-138. 
35. Pollitt, C. (2003). Joined-up Government: A Survey. Political Studies Review, vol.1, no 1, pp. 34-49.

36. Pollitt, C. \& Bouckaert, G. (2004). Public Management Reform: A Comparative Analysis. Oxford University Press, USA.

37. Pollitt, C. \& Bouckaert, G. (2017). Public management reform: A Comparative Analysis into the Age of Austerity: A Comparative Analysis into the Age Of Austerity. Oxford: Oxford University Press.

38. Powell, W. W., Koput, K. W. \& Smith-Doerr, L. (1996). Interorganizational Collaboration and the Locus of Innovation: Networks of Learning in Biotechnology. Administrative Science Quarterly, vol. 41. No 1, pp. 116-145.

39. Pratchett, L. (2003). H. Sullivan and C. Skelcher, Working Across Boundaries: Collaboration in Public Services. Parliamentary Affairs, vol. 56, no 2, pp. 379-379.

40. Rhodes, R. A. (1997). Understanding Governance: Policy Networks, Governance, Reflexivity and Accountability. Open University press.

41. Schedler, K. \& Proeller, I. (2007). Cultural Aspects of Public Management Reform. Emerald Group Publishing Limited.

42. Shergold, P. (2005). Regeneration: New Structures, New Leaders, New Traditions. Australian Journal of Public Administration, vol. 64, no 2, pp. 3-6.

43. Song, X. (2018). Governance and Public Service Delivery under the Labour Government. In: SONG, X. (ed.) Implementing Sure Start Policy: Context, Networks and Discretion. Singapore: Springer Singapore.

44. Sullivan, H. \& Skelcher, C. (2017). Working Across Boundaries: Collaboration in Public Services. Macmillan International Higher Education.

45. Tony Blair \& Cunningham, J. (1999). Modernising Government. Available at: https://ntouk. files.wordpress.com/2015/06/modgov.pdf (accessed: 17 July, 2018).

46. Xi, J. (2016). Cultural Differences and Similarities between China and Brazil: A Comparative Analysis Using Hofstede's Cultural Dimensions. In: China and Latin America in Transition, pp. 227-242. Available at: DOI: 10.1057/978-1-137-54080-5_13 (accessed: 30 January, 2019). 